\title{
Civic science literacy in Thailand: the role of scientific communities to support lifelong learning
}

\author{
Ganigar Chen $^{\mathrm{a}, *}$, Pichai Sonchaeng ${ }^{\mathrm{b}}$, Archanya Ratana-ubol ${ }^{\mathrm{c}}$ \\ a National Science Museum, Technopolis, Pathum Thani 12120 Thailand \\ b Office of Science Technology and Innovation Collaboration, Chulabhorn Royal Academy, Bangkok \\ 10210 Thailand \\ c Department of Lifelong Education, Faculty of Education, Chulalongkorn University, Bangkok 10330 \\ Thailand \\ *Corresponding author, e-mail: ganigar@hotmail.com
}

Early in 1936, a group of passionate young Thai scholars who had studied abroad initiated scientific activities, such as films and lectures, and eventually founded the Science Society of Thailand in $1948^{1}$. Over the past eighty years, a number of organizations and interested agencies have been established and involved in various activities to promote science in Thailand. At present, there are hundreds of participating organizations involved in the promotion of science learning activities in formal, nonformal and informal settings. These organizations include official agencies directly responsible for national capacity building such as agencies under the Ministry of Education, research agencies that also set aside resources to help promote talents in certain scientific fields, lifelong learning agencies such as museums and learning centers, as well as the private sector. Most activities or projects are usually aimed at promoting interest and inspiration in science, in addition to providing educational scientific engagement in order to encourage studies and careers in science-related disciplines.

Despite the numerous agencies involved in promoting science learning, the national competitiveness index that includes science literacy continues to be ranked below average compared to those of Organization for Economic Cooperation Development (OECD) countries ${ }^{2}$. A survey conducted among policy experts in the field suggested that there are barriers and possibilities to promote science literacy in Thailand ${ }^{3,4}$. Interviews conducted with science education policy experts revealed some challenges that the country encountered in the past years and has yet to overcome. One challenge is the public perception of science, especially of parents. Even though parents consider science to be important for their children and support science education, it is because science is an important subject in entrance examinations that will allow their children to enter good schools or universities, or popular professional fields of study in higher education such as medicine or engineering. Another challenge is the lack of common and specific goals among all the agencies involved in promoting science learning. Most activities are independently developed and implemented in small scales. Other challenges include poor communication and/or lack of information transfer on current science and technology issues to the general public. Therefore, Thailand or other countries trying to prepare their citizens for the rapidly changing world would have to re-evaluate their goals in promoting science literacy and look for alternatives in engaging the general public towards science in order to convince people of its benefits in the futuristic world.

Shen ${ }^{5}$ proposed three types of science literacy, namely practical, civic and cultural science literacy. The three categories are different in terms of their objectives, audience, contents, formats, and means of delivery. Practical scientific literacy is the possession of scientific knowledge that can be used to help solve practical problems in an individual's life. Civic scientific literacy takes it further towards the goal of informed public policy making by enabling citizens to become sufficiently aware of science and science-related public issues in order for the average citizen to become involved in the decision-making process regarding issues, e.g., health, energy, natural resources, food, and the environment. Cultural scientific literacy is derived from different motives as it is driven by the desire to know something about science as an achievement to mankind.

Therefore, it would be worthwhile for scientific communities with noble intentions, which have 
been attempting to promote and communicate science to society to ensure that science and research become public assets and contribute to improved quality of life and people's well-being, and to refocus their target audience for science literacy, i.e., especially to the general public or adults. To become science literate, one should have good knowledge of basic or advanced science in addition to having the ability to continue learning and make informed decisions in the technology-oriented world. The advancement in information technology today has allowed for the increased possibility of lifelong learning. However, knowing facts may not be as important as knowing how to find the right facts from reliable sources and applying that knowledge to come up with solutions to daily problems or make public decisions that will have long-term impacts on our lives and the environment. Scientific societies and agencies that promote lifelong education in science may have to make further attempts to provoke critical thinking on scientific issues related to public well-being, such as renewable energy, longevity, bioethics, or digital economy, by bringing different aspects of their research and exchanging ideas with the public. In various countries, the media, scientists and science communicators work systematically together to set communication agendas for the public, as well as listen to public voices in their quest for scientific explanation. The Science Media Centers in the United Kingdom and Australia were effective in engaging adults in science and research. However, this model requires tremendous effort and commitment from scientific communities. Interestingly, a recent survey conducted in Thailand revealed that Thai youths think that the most reliable source of scientific information is scientists ${ }^{3}$. Therefore, it is time for the scientific community to realize that we need to promote science for the public, by aiming at civic science literacy, in order to make science more relevant than for examinations in schools, and ensure that our current and next generation can exercise their rights as informed citizens in the democratic world.

The National Science Museum (NSM), a state enterprise under an umbrella of the Ministry of Higher Education, Science, Research and Innovation, was founded in 1993 with the mission to promote public interest and awareness of science and technology. Located in Pathum Thani, a northern province of Bangkok, NSM is headquartered in Technopolis and operates three interactive museums, including the Science Museum, Natural History Museum and Information Technology Museum. An upcoming new museum that would cover ecological and environmental issues is scheduled to be opened at the end of 2019. NSM's philosophy is to inspire every walk of life to value and appreciate science, and to cultivate a scientific culture that uses rational thinking to make informed decisions. Through more than two-hundred hands-on exhibits, and intensive educational and public programs, NSM engages Thais and the international audience with new and surprising experiences in science and technology. In addition, with its mission to popularize science, NSM also reaches out to nation-wide audiences through intensive outreach under a project called 'NSM Science Caravan', which brings hand-on science to almost every province in the country. NSM has taken on a new strategy in promoting civic science literacy, through the use of new tools such as debates, talks, and citizen science activities, along with media outreach and cultural events such as shows and drama, online science issues and on-air scientific TV programs, etc. Working as a platform to bridge scientific research and society, NSM also initiates linkages with media partners, research agencies, young scientists and academics to facilitate communication and interactions with the public on scientific issues, ethics and citizenship responsibility. We believe that through collaboration, scientific information can be widely accessed to support lifelong learning in order to ensure the well-being of people and the sustainability of the society.

\section{REFERENCES}

1. The Science Society of Thailand (1998) 50 Years The Science Society of Thailand Under The Patronage of H.M. The King, DanSutha Publishing, Bangkok.

2. Institute for the Promotion of Teaching Science and Technology (2015) Science Competencies for Tomorrow's World, Seven Printing Group, Bangkok.

3. Chen G (2019) Strategy development of lifelong education to enhance civic science literacy for Thai youth. $\mathrm{PhD}$ dissertation, Chulalongkorn Univ, Bangkok.

4. Laugksch RC (2000) Scientific literacy: A conceptual overview. Sci Educ 84, 71-94.

5. Shen BSP (1975) Science literacy and public understanding of science. In: Day SB (ed) Communication of Scientific Information, Karger Publishers, New York, pp 44-52. 